\title{
Gestational Age at Birth and Brain White Matter Development in Term-Born Infants and Children
}

(D) X. Ou, (D).M. Glasier, (D).H. Ramakrishnaiah, (D)A. Kanf, (D)A.C. Rowell, (DR.T. Pivik, (D)A. Andres, (D).A. Cleves, and (D).M. Badger O.

\begin{abstract}
BACKGROUND AND PURPOSE: Studies on infants and children born preterm have shown that adequate gestational length is critical for brain white matter development. Less is known regarding how variations in gestational age at birth in term infants and children affect white matter development, which was evaluated in this study.
\end{abstract}

MATERIALS AND METHODS: Using DTI tract-based spatial statistics methods, we evaluated white matter microstructures in 2 groups of term-born ( $\geq 37$ weeks of gestation) healthy subjects: 2-week-old infants $(n=44)$ and 8-year-old children $(n=63)$. DTI parameters including fractional anisotropy, mean diffusivity, axial diffusivity, and radial diffusivity were calculated by voxelwise and ROI methods and were correlated with gestational age at birth, with potential confounding factors such as postnatal age and sex controlled.

RESULTS: Fractional anisotropy values, which are markers for white matter microstructural integrity, positively correlated $(P<.05$, corrected) with gestational age at birth in most major white matter tracts/regions for the term infants. Mean diffusivity values, which are measures of water diffusivities in the brain, and axial and radial diffusivity values, which are markers for axonal growth and myelination, respectively, negatively correlated $(P<.05$, corrected) with gestational age at birth in all major white matter tracts/regions excluding the body and splenium of the corpus callosum for the term infants. No significant correlations with gestational age were observed for any tracts/regions for the term-born 8-year-old children.

CONCLUSIONS: Our results indicate that longer gestation during the normal term period is associated with significantly greater infant white matter development (as reflected by higher fractional anisotropy and lower mean diffusivity, axial diffusivity, and radial diffusivity values); however, similar associations were not observable in later childhood.

ABBREVIATIONS: $A D=$ axial diffusivty; $F A=$ fractional anisotropy; $M D=$ mean diffusivity; $R D=$ radial diffusivity

$\mathrm{t}$ is well known that infants born with low gestational age (preterm, $<37$ completed weeks of gestation) are relatively more vulnerable to brain white matter injury or abnormal white matter development. White matter damage in extremely or very preterm infants ( $<32$ completed weeks of gestation) is common, and increased risk is associated with lower gestational age ${ }^{1}$; white matter

Received March 23, 2017; accepted after revision July 22.

From the Departments of Radiology (X.O., C.M.G., R.H.R., A.K., A.C.R.) and Pediatrics (X.O., C.M.G., R.T.P., A.A., M.A.C., T.M.B.), University of Arkansas for Medical Sciences, Little Rock, Arkansas; Arkansas Children's Nutrition Center (X.O., R.T.P., A.A., T.M.B.), Little Rock, Arkansas; and Department of Radiology (X.O., C.M.G., R.H.R., A.K., A.C.R.), Arkansas Children's Hospital, Little Rock, Arkansas.

These studies were supported in part by United States Department of Agriculture Agricultural Research Service Project 6026-51000-010-05S and the Marion B. Lyon Award from the Arkansas Children's Research Institute.

Please address correspondence to Xiawei Ou, PhD, Arkansas Children's Hospital, 1 Children's Way, Slot 105, Little Rock, AR 72202; e-mail: ouxiawei@uams.edu

- Indicates open access to non-subscribers at www.ajnr.org

7 Indicates article with supplemental on-line photo.

http://dx.doi.org/10.3174/ajnr.A5408 microstructural differences in moderate or late preterm infants (32-36 completed weeks of gestation) compared with term infants have also been reported. ${ }^{2}$ The abnormality of white matter development associated with low gestational age in preterm infants may extend well beyond infancy, as indicated by observed differences in adolescents born prematurely compared with term-born controls. ${ }^{3-5}$ Furthermore, abnormal white matter development associated with preterm birth is also linked to adverse long-term neurodevelopmental outcomes in children at different ages. ${ }^{6-8}$

The effects of gestational age on neurologic or neurodevelopment for term-born children ( $\geq 37$ completed weeks of gestation) have not been investigated until recently. Several new studies (most of them population-based) reported positive associations between longer gestational age (excluding postterm, which is $\geq 42$ weeks of gestation) and better cognitive and/or neurodevelopment in term-born children, such as higher scores on Bayley scales of mental and motor development during the first year of life ${ }^{9,10}$; 
more school readiness and cognitive and educational ability at age 3 years ${ }^{11}$; higher intelligence quotient scores ${ }^{12}$ and less vulnerability to low early developmental index at age $6-7$ years ${ }^{13}$; greater reading, math, and achievement scores in the third grade ${ }^{14}$; and better test scores in elementary and middle school and higher probability of being gifted. ${ }^{15}$

Brain structural and functional development is directly related with neurodevelopment and cognitive performance in children. However, very few studies have addressed whether length of gestation at term birth is associated with differences in later brain development in children as measured by neuroimaging, particularly for white matter development (a recent study reported associations between longer gestation and higher brain gray matter density measured by MR imaging in term-born healthy 6-10year-old children ${ }^{16}$ ). In addition, although white matter maturation before and after term has been investigated via imaging studies, ${ }^{17}$ there is insufficient quantitative characterization of white matter maturation during the normal term period beyond the common perception that white matter is developing rapidly during this time. In each week of gestation and/or week of life during the term period, white matter continues to mature in patterns of posterior to anterior and central to peripheral. ${ }^{18} \mathrm{~A}$ few studies have evaluated white matter microstructures in relation to term gestational ages ${ }^{19,20}$; nevertheless, studies including white matter imaging data for term-born infants have mostly focused on the comparison to preterm, ${ }^{20,21}$ but not on the trajectory of white matter development in term-born infants during the normal term period. Nor is it clear whether gestational lengths at birth of termborn infants impact this trajectory and longer-term development into childhood. In this study, DTI measures were used to examine potential associations between gestational age at birth and brain white matter microstructural development in 2 well-characterized cohorts of healthy term-born subjects (2-week old infants and 8-year-old children).

\section{MATERIALS AND METHODS Study Population}

All study subjects were from the existing prospective Brain Power (ClinicalTrials.gov identifier: NCT00735423) or Glowing (ClinicalTrials.gov identifier: NCT01131117) research cohorts at the Arkansas Children's Nutrition Center, and all experimental procedures were approved by the institutional review board at the University of Arkansas for Medical Sciences with parental consent. Inclusion and exclusion criteria for these 2 research cohorts apply to this retrospective secondary analysis study. Briefly, all infants $(n=44)$ were born to healthy women with uncomplicated singleton pregnancy; had term gestation at birth ( $\geq 37$ completed weeks); were born with size appropriate for gestational age; and had no birth defects or congenital abnormalities and no medical issues at or after birth. All 8-year-old children $(n=63)$ were term-born ( $\geq 37$ completed weeks) with birth weight and current body mass index between the 5 th and 95 th percentile for age; were healthy with normal neurodevelopment; and had no history of neurologic impairment or injury, psychologic or psychiatric diagnoses, or any other serious illnesses or diseases. Reynolds Intellectual Assessment Scales of intelligence quotient were measured, and all subjects had composite intelligence quotient $>80$. All in- fants included in this study had an MR imaging examination of the brain during natural sleep at Arkansas Children's Hospital around age 2 weeks, which included conventional sequences to screen for apparent abnormalities and DTI for evaluation of white matter development, as part of the Glowing study. All 8-year-old children included in this study were scanned with similar DTI pulse sequences as part of the Brain Power study.

\section{MR Imaging Data Acquisition}

The MR imaging data were acquired by using a $1.5 \mathrm{~T}$ Achieva scanner (Philips Healthcare, Best, the Netherlands) with an 8-channel SENSE head coil (Philips Healthcare). Infants were fed approximately 30 minutes before the scan and wrapped by a MedVac infant immobilizer (CFI Medical Solutions, Fenton, MI). Mini muffs were used to block the noise from the scanner, a pulse oximeter probe was used to monitor oxygen saturation and heart rate, and an MR imaging-compatible camera was used to monitor the infants during the scan. Pulse sequences included diffusion, susceptibility, 3D T1- and/or T2-weighted imaging to exclude apparent brain abnormalities, and a single-shot spinecho EPI sequence with diffusion-weighting gradients in 15 uniformly distributed directions and a maximum b-value of 700 seconds $/ \mathrm{mm}^{2}$ to acquire DTI data with $2 \times 2 \times 3 \mathrm{~mm}^{3}$ voxel size. For 8-year-old children, a headset was used to block scanner noise and to play audio associated with a movie played during the scan by using an MR imaging-compatible entertainment system. The children were instructed to remain still inside the scanner, but were given a panic button for emergency use. DTI data were acquired by using a similar EPI sequence with 15 diffusion-weighting directions and a maximum b-value of 800 seconds $/ \mathrm{mm}^{2}$.

\section{DTI Data Analysis}

All DTI raw data were exported to a workstation with the FMRIB Software Library (FSL, created by the Oxford Center for Functional MR Imaging of the Brain, United Kingdom [http://www. fmrib.ox.ac.uk/fsl]) installed on a VMware Linux virtual machine (VMware, Palo Alto, California) and with Matlab software (MathWorks, Natick, Massachusetts). First, FSL tools were used for eddy current and head movement correction in the raw data and for creating a brain mask for each subject. The preprocessed DTI data were then fed to the DTIfit tool (http://fsl.fmrib.ox. ac.uk/fsl/fsl-4.1.9/fdt/fdt_dtifit.html) to calculate DTI parameter maps for each subject, including fractional anisotropy (FA), mean diffusivity (MD), axial diffusivity (AD), and radial diffusivity (RD). The FA maps were then processed by the tract-based spatial statistics tool (http://fsl.fmrib.ox.ac.uk/fsl/fslwiki/TBSS) for further analysis. ${ }^{22}$ Specifically, FA maps were preprocessed to remove outliers from the DTI fitting and then aligned to each other to identify a most representative subject with the least total imaging warping. The FA maps for all subjects were then registered to the FA maps for this representative subject by using nonlinear transformation and were skeletonized by using the tract-based spatial statistics tool. A threshold of FA $>0.1$ was chosen for the infants' data and a threshold of FA $>0.15$ was chosen for the 8 -year-old children's data to delineate the major white matter tracts (white matter skeletons) on the FA maps for each subject, 
which were used for voxelwise statistical analysis. In addition, the $\mathrm{MD}, \mathrm{AD}$, and $\mathrm{RD}$ maps were transformed and skeletonized according to the existing template and logistics for FA maps and were processed for voxelwise statistical analysis as well. Furthermore, major white matter tracts/regions with known anatomy were sketched on the FA maps, and mean DTI parameter values for each ROI for each subject were exported to Matlab for additional ROI analysis.

\section{Statistics}

Randomization with 5000 permutations was used for the voxelwise correlation analysis in tract-based spatial statistics. The threshold-free cluster enhancement option ${ }^{23}$ was used to identify voxels with significant correlation $(P<.05$, corrected for multiple comparisons) between gestational age and DTI parameters. The analysis was also adjusted for potential confounding factors including postnatal age at MR imaging and the subject's sex, because the brain continues to develop rapidly after birth and sex differences in DTI measures in children have been reported. ${ }^{24}$ For the ROI analysis, Spearman partial correlation tests were used to calculate the coefficients and $P$ values for the correlation between gestational ages and mean DTI parameters in each ROI, controlling for postnatal age at MR imaging and sex.

\section{RESULTS}

The demographic information for the healthy term infants and 8 -year-old healthy children are listed in Table 1 . The standard deviation of age at the time of MR imaging examination was relatively small compared with the mean age at MR imaging for both groups, indicating well-defined age groups with potentially low confounding by postnatal age.

For the term infants, DTI tract-based spatial statistics analysis revealed that FA values, a marker for white matter microstructural integrity, positively correlated $(P<.05$, corrected) with gestational age at birth in most white matter voxels in the brain (Fig 1 and Table 2). These voxels involved the frontal, parietal, temporal, and occipital lobes and the pons as well as the cerebellum. However, the corpus callosum (especially the splenium and the body), which develops the fastest at the first trimester of pregnancy, ${ }^{25}$ did not show significant correlations. On the other hand, $\mathrm{MD}, \mathrm{AD}$, and $\mathrm{RD}$ parameters negatively correlated $(P<.05$, corrected) with gestational age at birth in most white matter voxels in the brain (Fig 1 and Table 2), again with the exception of the splenium and body of the corpus callosum. For the 8-year-old children, no voxels in the white matter tracts showed significant correlation (positive or

Scales.

${ }^{a}$ Unit for infant ages is weeks; for children, years.

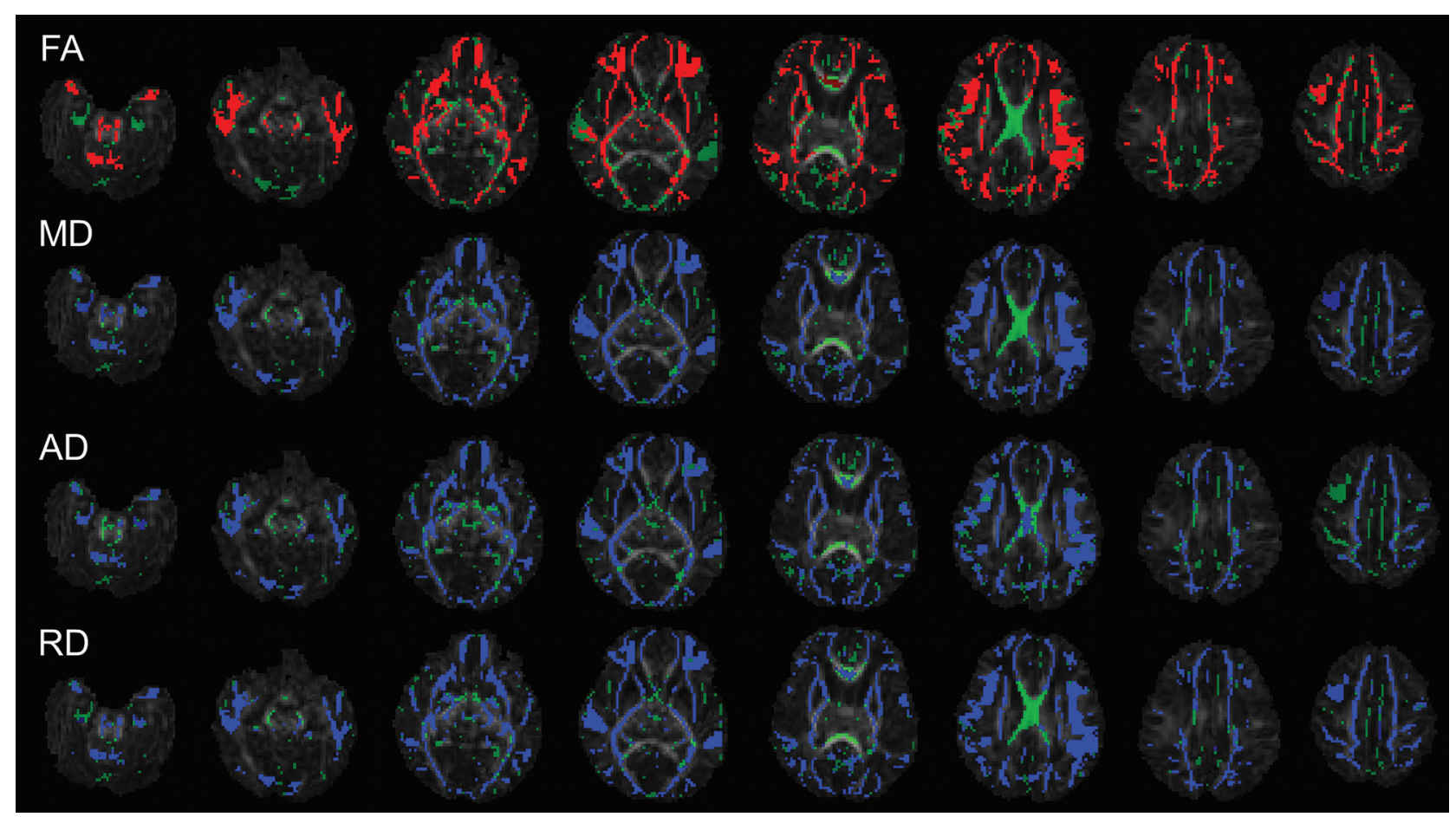

FIG 1. Tract-based spatial statistics analysis of the correlation between gestational age at birth and DTI parameters (FA, MD, AD, and RD) in term infants. Background images are FA maps; major white matter tracts are green; voxels in the tract with significant positive correlations $(P<.05$, corrected) are red; voxels with significant negative correlations $(P<.05$, corrected) are blue. Widespread positive correlations between FA and gestational age at birth and negative correlations between MD, AD, and RD and gestational age at birth were observed. 
negative) between gestational age at birth and any of the DTI parameters (Table 2). Sex effects on DTI parameter values were observed in several white matter tracts for the 8-year-old children (data presented in the On-line Figure), but were not observed for the term infants.

ROI analysis of brain white matter regions/tracts showed results similar to those observed for the tract-based spatial statistics

Table 2: Percentage of imaging voxels in major white matter tracts that showed significant correlation $(P<.05$, corrected $)$ between DTI parameters (FA, MD, AD, and RD) and gestational age at birth

\begin{tabular}{llc}
\hline & \multicolumn{1}{c}{ Infants $^{\mathbf{a}}$} & Children $^{\mathbf{a}}$ \\
\hline FA & 80, all positive & 0 \\
MD & 91, all negative & 0 \\
AD & 87, all negative & 0 \\
RD & 91, all negative & 0 \\
\hline
\end{tabular}

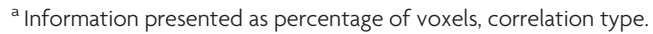
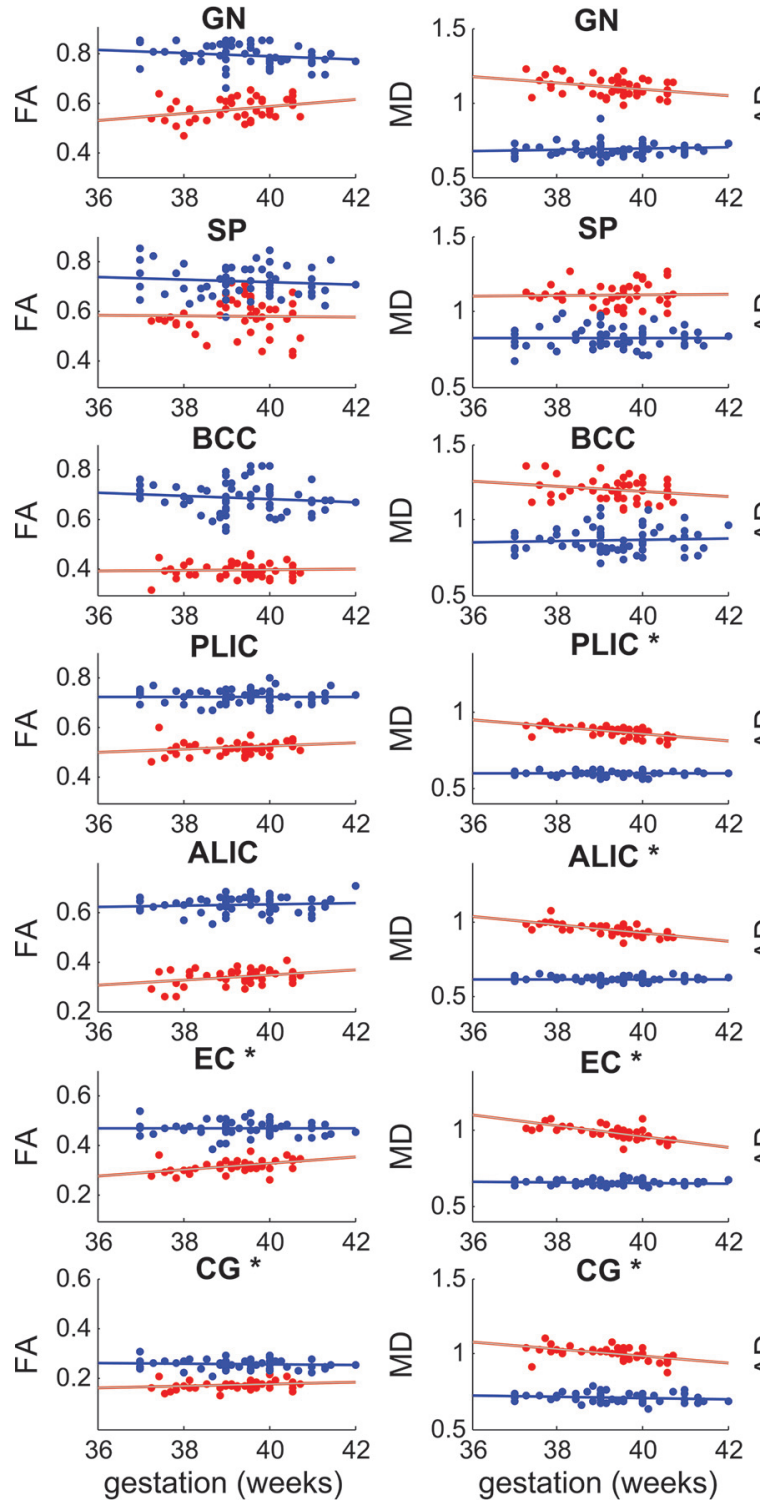

analyses (Fig 2). Correlation coefficients and $P$ values for all ROIs for the 2 study groups are listed in Table 3. For the term infants, of the 14 regions/tracts included, mean FA values positively correlated $(P<.05)$ with gestational age at birth in 6 regions, and mean $\mathrm{MD}, \mathrm{AD}$, and $\mathrm{RD}$ values negatively correlated $(P<.05)$ with gestational age at birth in 11 regions. The genu, splenium, and body of the corpus callosum did not show any significant correlations. For the 8-year-old children, no ROI showed a significant correlation $(P<.05)$ between gestational age at birth and any DTI parameter (Fig 2 and Table 3 ).

\section{DISCUSSION}

Our DTI study shows that gestational age at birth is associated with significant differences in white matter microstructural development in term infants, but not in term-born children at age 8
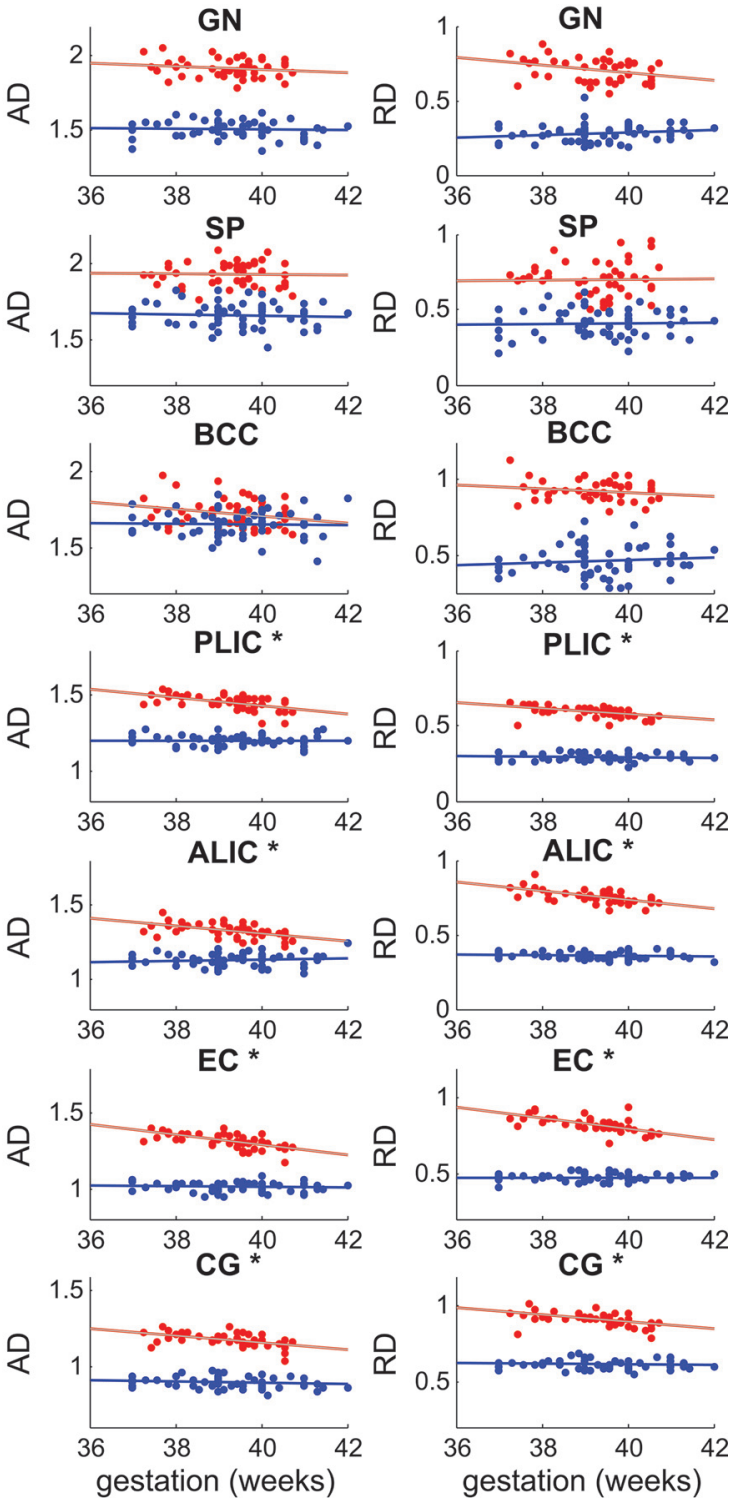

FIG 2. Scatterplots for correlation analyses between gestational age at birth and DTI parameters in white matter ROIs of term infants and children. Data for term infants are in red, and data for 8-year-old children are in blue. Least-square fit lines are also shown. Units for DTI parameters are: FA (no unit); MD, AD, and RD $\left(\mu \mathrm{m}^{2} / \mathrm{ms}\right)$. Positive correlations $(P<.05)$ between gestational age and FA were observed in many ROIs (marked with an asterisk) for the term infants, but not in any ROI for the 8-year-old children. Likewise, negative correlations $(P<.05)$ between gestational age and MD, AD, and RD were observed for most ROls (marked with an asterisk) for the term infants, but none were observed for any ROI for the 8-year-old children. (Details of correlation statistics are provided in Table 3.) 
$S C R$ *
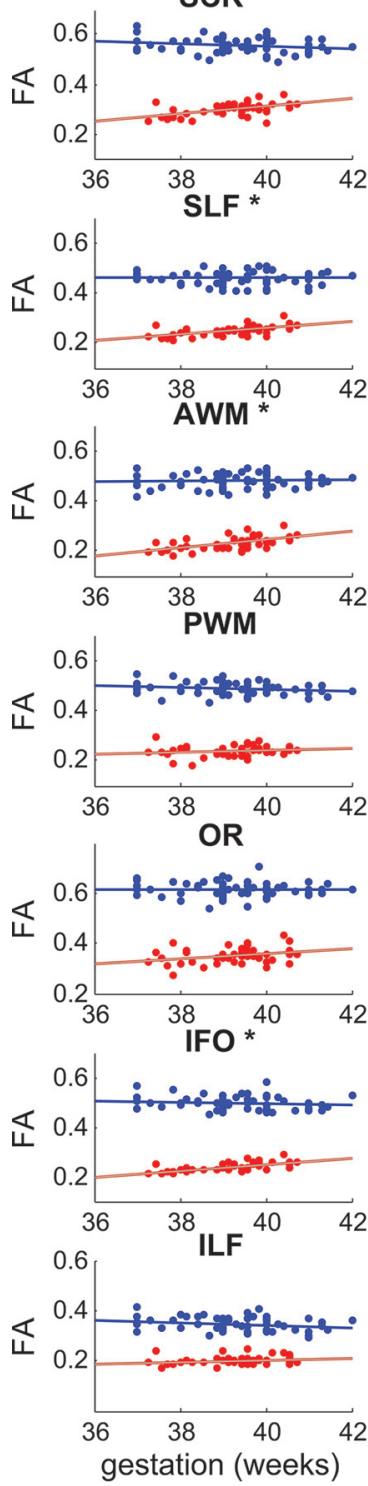
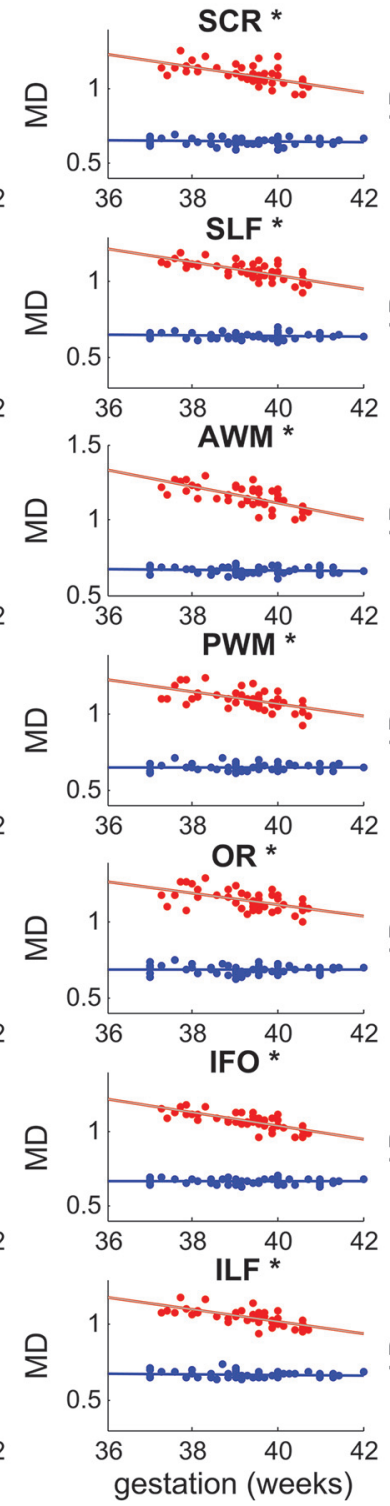
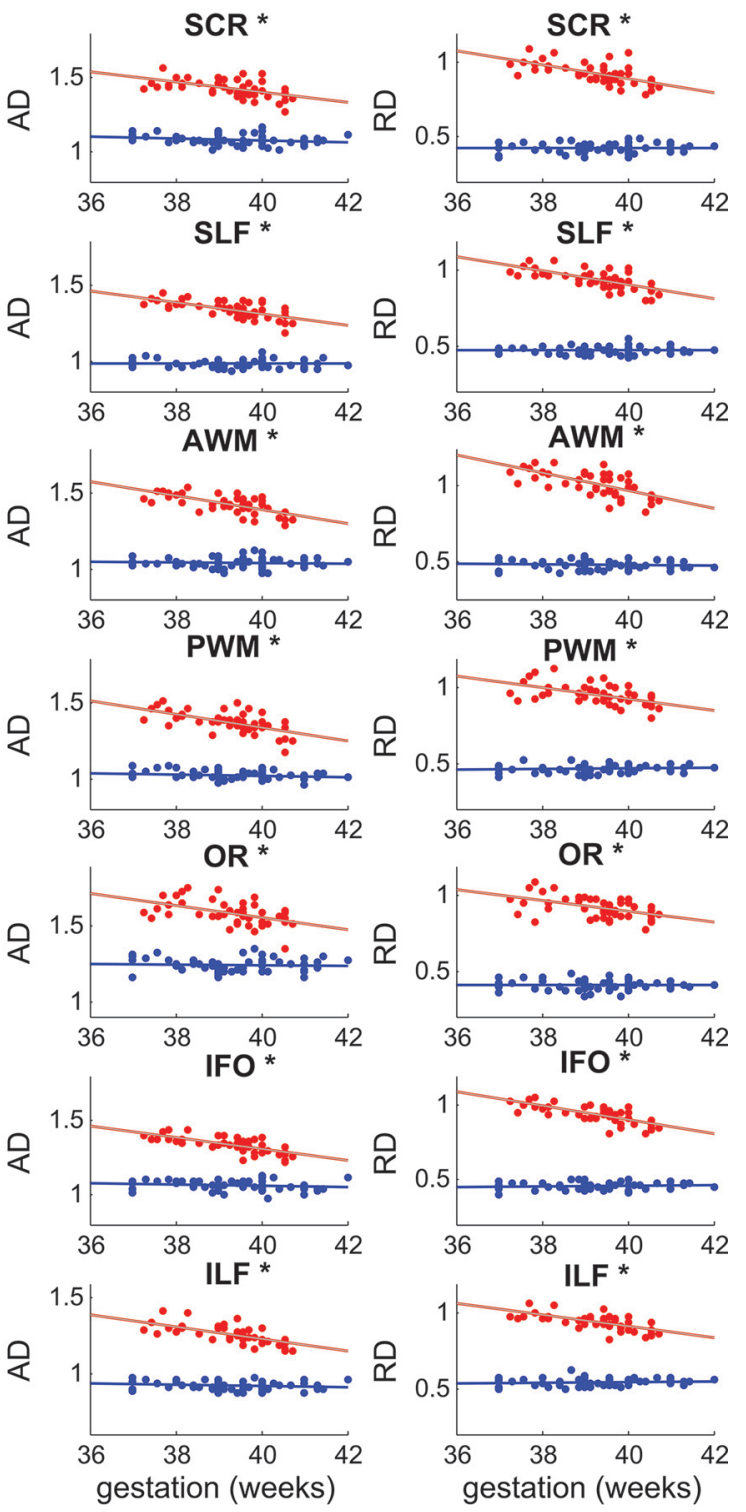

FIG 2. Continued.

years. Specifically, for term infants, significant positive correlations between gestational age at birth and FA values and negative correlations between gestational age at birth and $\mathrm{MD}, \mathrm{AD}$, and $\mathrm{RD}$ values were observed in most white matter tracts, indicating that increased myelination (reflected by lower RD) and axonal growth (reflected by lower $\mathrm{AD}$ ) as well as overall higher white matter integrity (reflected by higher FA and lower MD) are associated with longer gestational age during the normal term period before birth. One major white matter region not displaying these significant gestation-related associations was the corpus callosum, which typically starts development at the first trimester of pregnancy with a faster growth rate than at other trimesters. ${ }^{25} \mathrm{It}$ is possible that the development of the corpus callosum is less vulnerable to gestational influences at the end of the normal term period, in which case relatively small differences in gestational age within the normal term period may not result in measurable changes in its myelination and growth. For the DTI parameters, it appears that diffusivity measures $(\mathrm{MD}, \mathrm{AD}$, and $\mathrm{RD}$ ) were more sensitive than anisotropy (FA) to white matter microstructural changes during the normal term period. For example, tract-based spatial statistics analyses revealed a higher percentage of white matter voxels with significant correlations related to gestational age at birth (Table 2) for MD, AD, and RD than for FA, and ROI analyses showed significant correlations with gestational age at birth for more regions for $\mathrm{MD}, \mathrm{AD}$, and $\mathrm{RD}$ than for $\mathrm{FA}$ (Table 3). To our knowledge, there is only 1 other published study focused on white matter microstructural development in term infants at young postnatal ages similar to those in our study. ${ }^{20}$ In that study, a positive correlation with gestational age was found in several white matter regions for FA values. Analyses on diffusivities were not available. Another study investigated white matter microstructural development in term infants at a larger postnatal age range by using DTI tractography methods, but the evaluation was limited to only a few white matter regions. ${ }^{19}$ Their results showed increased FA and decreased MD with gestational age at MR imaging (gestational age at birth plus postnatal age at MR imaging) in corticospinal tracts, but not in the splenium of the corpus callosum, consistent with our findings. Overall, our DTI results for 
Table 3: Correlation coefficients ( $r$ values) and correlation statistics ( $P$ values) between gestational age at birth and DTI parameters in white matter ROls for the term infants and children

\begin{tabular}{|c|c|c|c|c|c|c|c|c|}
\hline & \multicolumn{2}{|c|}{ FA Correlation } & \multicolumn{2}{|c|}{ MD Correlation } & \multicolumn{2}{|c|}{ AD Correlation } & \multicolumn{2}{|c|}{ RD Correlation } \\
\hline & $r$ Value & $P$ Value & $r$ Value & $P$ Value & $r$ Value & $P$ Value & $r$ Value & $P$ Value \\
\hline \multicolumn{9}{|l|}{ Infants } \\
\hline $\mathrm{GN}$ & 0.28 & .07 & -0.24 & .13 & -0.06 & .72 & -0.29 & .06 \\
\hline SP & -0.02 & .90 & 0.06 & .73 & -0.05 & .78 & 0.06 & .69 \\
\hline $\mathrm{BCC}$ & -0.06 & .70 & -0.15 & .34 & -0.25 & .10 & -0.08 & .60 \\
\hline PLIC & 0.29 & .06 & -0.67 & $<.001^{\mathrm{a}}$ & -0.54 & $<.001^{\mathrm{a}}$ & -0.59 & $<.001^{\mathrm{a}}$ \\
\hline ALIC & 0.18 & .25 & -0.72 & $<.001^{\mathrm{a}}$ & -0.59 & $<.001^{\mathrm{a}}$ & -0.61 & $<.001^{\mathrm{a}}$ \\
\hline EC & 0.45 & $.003^{\mathrm{a}}$ & -0.71 & $<.001^{\mathrm{a}}$ & -0.65 & $<.001^{\mathrm{a}}$ & -0.69 & $<.001^{\mathrm{a}}$ \\
\hline CG & 0.32 & $.04^{a}$ & -0.63 & $<.001^{\mathrm{a}}$ & -0.51 & $<.001^{\mathrm{a}}$ & -0.62 & $<.001^{\mathrm{a}}$ \\
\hline SCR & 0.48 & $.001^{\mathrm{a}}$ & -0.63 & $<.001^{\mathrm{a}}$ & -0.54 & $<.001^{\mathrm{a}}$ & -0.63 & $<.001^{\mathrm{a}}$ \\
\hline SLF & 0.59 & $<.001^{\mathrm{a}}$ & -0.65 & $<.001^{\mathrm{a}}$ & -0.63 & $<.001^{\mathrm{a}}$ & -0.66 & $<.001^{\mathrm{a}}$ \\
\hline AWM & 0.60 & $<.001^{\mathrm{a}}$ & -0.69 & $<.001^{\mathrm{a}}$ & -0.66 & $<.001^{\mathrm{a}}$ & -0.67 & $<.001^{\mathrm{a}}$ \\
\hline PWM & 0.23 & .13 & -0.59 & $<.001^{a}$ & -0.61 & $<.001^{\mathrm{a}}$ & -0.52 & $<.001^{\mathrm{a}}$ \\
\hline OR & 0.28 & .07 & -0.52 & $<.011^{\mathrm{a}}$ & -0.49 & $.001^{\mathrm{a}}$ & -0.47 & $.001^{\mathrm{a}}$ \\
\hline IFO & 0.66 & $<.001^{\mathrm{a}}$ & -0.72 & $<.001^{\mathrm{a}}$ & -0.70 & $<.001^{\mathrm{a}}$ & -0.70 & $<.001^{\mathrm{a}}$ \\
\hline ILF & 0.24 & .13 & -0.71 & $<.001^{\mathrm{a}}$ & -0.69 & $<.001^{\mathrm{a}}$ & -0.68 & $<.001^{\mathrm{a}}$ \\
\hline \multicolumn{9}{|l|}{ Children } \\
\hline GN & -0.25 & .05 & 0.16 & .21 & -0.15 & .25 & 0.22 & .08 \\
\hline $\mathrm{SP}$ & -0.05 & .68 & 0.04 & .78 & -0.03 & .79 & 0.04 & .78 \\
\hline $\mathrm{BCC}$ & -0.13 & .33 & 0.03 & .81 & 0.00 & .99 & 0.06 & .63 \\
\hline PLIC & -0.03 & .81 & -0.02 & .88 & -0.04 & .73 & 0.01 & .93 \\
\hline ALIC & 0.08 & .54 & -0.05 & .68 & 0.09 & .51 & -0.10 & .46 \\
\hline $\mathrm{EC}$ & -0.05 & .69 & -0.00 & .95 & -0.07 & .61 & 0.01 & .93 \\
\hline CG & -0.08 & .53 & -0.19 & .14 & -0.02 & .10 & -0.16 & .21 \\
\hline SCR & -0.17 & .18 & -0.02 & .91 & -0.24 & .06 & 0.04 & .77 \\
\hline SLF & 0.01 & .95 & -0.01 & .94 & -0.02 & .84 & -0.02 & .89 \\
\hline AWM & -0.01 & .91 & -0.10 & .44 & -0.06 & .64 & -0.09 & .49 \\
\hline PWM & -0.19 & .14 & -0.00 & .97 & -0.18 & .17 & 0.08 & .52 \\
\hline OR & -0.04 & .76 & -0.05 & .72 & -0.00 & .99 & -0.04 & .77 \\
\hline IFO & -0.21 & .10 & -0.04 & .77 & -0.22 & .09 & 0.05 & .71 \\
\hline ILF & -0.21 & .10 & 0.00 & .98 & -0.24 & .06 & 0.10 & .43 \\
\hline
\end{tabular}

Note:-ALIC indicates anterior limb of internal capsule; AWM, anterior white matter; BCC, body of corpus callosum; CG, cingulum; EC, external capsule; GN, genu of corpus callosum; IFO, inferior frontal occipital fasciculus; ILF, inferior longitudinal fasciculus; OR, optic radiation; PLIC, posterior limb of internal capsule; PWM, posterior white matter; SCR, superior corona radiata; SLF, superior longitudinal fasciculus; SP, splenium of corpus callosum.

${ }^{a}$ Indicates $P$ values for significant correlations.

term infants agree with the general consensus that the normal term period (37-41 weeks of gestation) is a critical timeframe for the developing brain. Furthermore, the results in the current study can provide additional normative data for DTI parameter changes in white matter during this period.

For 8-year-old term-born children, significant correlations between gestational age at birth and DTI parameters at age 8 years were not observed. This may be a reflection of a "catch-up" effect (ie, the deficits presumably related to less in utero development because of shorter gestational length within the normal term period were compensated for during 8 years of postnatal development, with the white matter microstructures in term-born children with all gestational ages eventually reaching the same level). However, extensive exposure to potential confounding factors (such as diet, lifestyle, and family environment) during the 8 years of postnatal brain development could also be a mediating factor and cannot be ruled out as a contributing factor underlying the observed absence of gestational age-associated white matter differences. Although there was no significant correlation between gestational age and intelligence quotient for the 8-year-old children $(r=-0.09, P=.49)$ in our study, population-based studies have shown that white matter development is associated with cognitive functioning in 6-10-year-old healthy children, ${ }^{18}$ and recent large-scale studies have revealed associations between cogni- tive development and length of gestation in school-age children born at term. ${ }^{12-15}$ Our results indicate that white matter changes are not likely the driving force for reported relationships between gestational age and cognitive performance in term-born children. It is noteworthy that reported white matter changes in older children/ adolescents associated with preterm birth were mostly for those born very preterm or with very low birth weight, ${ }^{3-5,8,26}$ and a study of 9-year-old children with low risk preterm birth (30-34 weeks of gestation) showed more changes in gray matter than white matter compared with term controls. ${ }^{27}$ In addition, 1 study showed increased regional gray matter attenuation associated with gestational age at birth in 6-10-year-old children for both the preterm and term subgroups. ${ }^{16}$ Therefore, the development of gray matter, the other major structural component of the brain, may need to be the future focus for exploring potential relationships between gestational age and brain development in term-born children. This may be achieved by either global/regional volume or cortical thickness measurements of gray matter or fMRI measurements of stimulated brain activation or connectivity at resting state in gray matter.

One limitation for this study is that the gestational age for the 8 -year-old children was parent reported. Medical records containing relevant information were not available for some subjects. Parents were asked to provide the due date (and/or the exact gestational length at birth of their children) as part of the Brain 
Power study (those unable to provide this information were excluded from this study), and gestational age at birth was then calculated by comparing the due date (assume 40 weeks of gestation) and the actual date of birth. Although potential inaccuracy (likely on the order of days, if any) is possible, the distribution and mean/standard deviation (Table 1) of gestational age at birth were comparable with that for the infant cohort, and therefore did not suggest apparent issues. Furthermore, additional analyses were performed to test the effects of gestational age at term birth on DTI parameters in these 8-year-old children, such as group comparisons of those with reported gestational age 37-38 completed weeks versus $39-41$ or $40-41$ completed weeks; 37 or 38 completed weeks versus 39, 40, or 41 completed weeks; and so forth. None of those comparisons showed any effect of gestational age at birth on DTI parameters for the 8-year-old children.

\section{CONCLUSIONS}

Our DTI findings indicate that longer gestational length is associated with greater white matter microstructural development in term healthy infants, but not in term-born 8 -year-old healthy children.

\section{ACKNOWLEDGMENTS}

We thank the staff of the Arkansas Children's Nutrition Center Clinical Research Core and the Arkansas Children's Hospital Radiology MR imaging team for their assistance with these studies. We also thank Dr. Sean Adams and Dr. Sherry Courtney for helpful discussion as well as reviewing this manuscript.

Disclosures: Xiawei Ou—RELATED: Grants/Grants Pending: United States Department of Agriculture (USDA) grant, Comments: this study was partly supported by a USDA Agricultural Research Service (USDA-ARS) grant, which is acknowledged in the manuscript*. Charles M. Glasier-UNRELATED: Board Membership: Pediatric Radiology, Comments, editorial board; Arkansas Foodbank. R.T. Pivik—RELATED: Grants/ Grants Pending: USDA-ARS*; Support for Travel to Meetings for the Study or Other Purposes: USDA-ARS*; Provision of Writing Assistance, Medicines, Equipment, or Administrative Support: USDA-ARS*; UNRELATED: Grants/Grants Pending: USDA-ARS*. Aline Andres-RELATED: Grants/Grants Pending: USDA-ARS*; Support for Travel to Meetings for the Study or Other Purposes: USDA-ARS, Comments: grant-supported travel to scientific conferences*. *Money paid to the institution.

\section{REFERENCES}

1. Larroque B, Marret S, Ancel PY, et al. White matter damage and intraventricular hemorrhage in very preterm infants: the EPIPAGE study. J Pediatr 2003;143:477-83 CrossRef Medline

2. Kelly CE, Cheong JL, Fam LG, et al. Moderate and late preterm infants exhibit widespread brain white matter microstructure alterations at term-equivalent age relative to term-born controls. Brain Imaging Behav 2016;10:41-49 CrossRef Medline

3. Giménez M, Junqué C, Narberhaus A, et al. White matter volume and concentration reductions in adolescents with history of very preterm birth: a voxel-based morphometry study. Neuroimage 2006;32:1485-98 CrossRef Medline

4. Nagy Z, Westerberg H, Skare S, et al. Preterm children have disturbances of white matter at 11 years of age as shown by diffusion tensor imaging. Pediatr Res 2003;54:672-79 CrossRef Medline

5. Vangberg TR, Skranes J, Dale AM, et al. Changes in white matter diffusion anisotropy in adolescents born prematurely. Neuroimage 2006;32:1538-48 CrossRef Medline

6. Counsell SJ, Edwards AD, Chew AT, et al. Specific relations between neurodevelopmental abilities and white matter microstructure in children born preterm. Brain 2008;131:3201-08 CrossRef Medline

7. Feldman HM, Lee ES, Yeatman JD, et al. Language and reading skills in school-aged children and adolescents born preterm are associated with white matter properties on diffusion tensor imaging. Neuropsychologia 2012;50:3348-62 CrossRef Medline

8. Murray AL, Thompson DK, Pascoe L, et al. White matter abnormalities and impaired attention abilities in children born very preterm. Neuroimage 2016;124:75-84 CrossRef Medline

9. Espel EV, Glynn LM, Sandman CA, et al. Longer gestation among children born full term influences cognitive and motor development. PLoS One 2014;9:e113758 CrossRef Medline

10. Rose O, Blanco E, Martinez SM, et al. Developmental scores at 1 year with increasing gestational age, 37-41 weeks. Pediatrics 2013;131: E1475-81 CrossRef Medline

11. Poulsen G, Wolke D, Kurinczuk JJ, et al. Gestational age and cognitive ability in early childhood: a population-based cohort study. Paediatr Perinat Epidemiol 2013;27:371-79 CrossRef Medline

12. Yang S, Platt RW, Kramer MS. Variation in child cognitive ability by week of gestation among healthy term births. Am J Epidemiol 2010; 171:399-406 CrossRef Medline

13. Smithers LG, Searle AK, Chittleborough CR, et al. A whole-of-population study of term and post-term gestational age at birth and children's development. BJOG 2015;122:1303-11 CrossRef Medline

14. Noble KG, Fifer WP, Rauh VA, et al. Academic achievement varies with gestational age among children born at term. Pediatrics 2012; 130:e257-64 CrossRef Medline

15. Figlio DN, Guryan J, Karbownik K, et al. Long-term cognitive and health outcomes of school-aged children who were born late-term vs full-term. JAMA Pediatr 2016;170:758-64 CrossRef Medline

16. Baym CL, Khan NA, Monti JM, et al. Dietary lipids are differentially associated with hippocampal-dependent relational memory in prepubescent children. Am J Clin Nutr 2014;99:1026-32 CrossRef Medline

17. Dubois J, Dehaene-Lambertz G, Kulikova S, et al. The early development of brain white matter: a review of imaging studies in fetuses, newborns and infants. Neuroscience 2014;276:48-71 CrossRef Medline

18. Muetzel RL, Mous SE, van der Ende J, et al. White matter integrity and cognitive performance in school-age children: a population-based neuroimaging study. Neuroimage 2015;119:119-28 CrossRef Medline

19. Alcauter S, Lin W, Keith Smith J, et al. Consistent anterior-posterior segregation of the insula during the first 2 years of life. Cereb Cortex 2015;25:1176-87 CrossRef Medline

20. Broekman BF, Wang C, Li Y, et al. Gestational age and neonatal brain microstructure in term born infants: a birth cohort study. PLoS One 2014;9:e115229 CrossRef Medline

21. Davids S, Lauffer H, Thoms K, et al. Increased dorsolateral prefrontal cortex activation in obese children during observation of food stimuli. Int J Obesity (Lond) 2010;34:94-104 CrossRef Medline

22. Smith SM, Jenkinson M, Johansen-Berg H, et al. Tract-based spatial statistics: voxelwise analysis of multi-subject diffusion data. Neuroimage 2006;31:1487-505 CrossRef Medline

23. Smith SM, Nichols TE. Threshold-free cluster enhancement: addressing problems of smoothing, threshold dependence and localisation in cluster inference. Neuroimage 2009;44:83-98 CrossRef Medline

24. Schmithorst VJ, Holland SK, Dardzinski BJ. Developmental differences in white matter architecture between boys and girls. Hum Brain Mapp 2008;29:696-710 CrossRef Medline

25. Achiron R, Achiron A. Development of the human fetal corpus callosum: a high-resolution, cross-sectional sonographic study. $U l$ trasound Obstet Gynecol 2001;18:343-47 CrossRef Medline

26. Nosarti C, Giouroukou E, Healy E, et al. Grey and white matter distribution in very preterm adolescents mediates neurodevelopmental outcome. Brain 2008;131:205-17 CrossRef Medline

27. Soria-Pastor S, Padilla N, Zubiaurre-Elorza L, et al. Decreased regional brain volume and cognitive impairment in preterm children at low risk. Pediatrics 2009;124:e1161-70 CrossRef Medline 